\title{
Removing lumen-apposing metal stent stopped bleeding from splenic artery pseudoaneurysm during transmural drainage of walled-off pancreatic necrosis
}

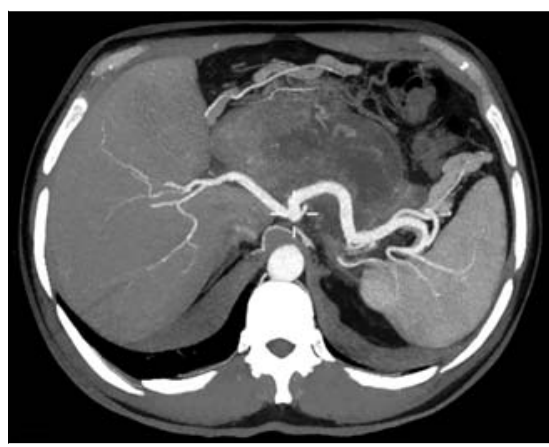

- Fig. 1 Computed tomography scan showed a collection of about $8.6 \times 6 \mathrm{~cm}$ with a liquid component of 4 to $6 \mathrm{~cm}$ and some necrotic areas inside, near the body/ tail of the pancreas.

A 45-year-old man with a walled-off pancreatic necrosis underwent endoscopic ultrasound (EUS)-guided transmural drainage using a lumen-apposing metal stent (LAMS) owing to infection and gastric outlet obstruction [1]. His clinical history included previous necrotizing pancreatitis with a splenic vein thrombosis and a laparoscopic cholecystectomy. Chronic medication included proton pump inhibitors.

Both the initial computed tomography (CT) scan ( $\mathbf{F i g . ~} \mathbf{1}$ ) and the EUS (> Fig. 2 ) showed a collection with a liquid component and some necrotic areas inside (about 30\%), near the body/tail of the pancreas and in close contact with the splenic artery. A double pigtail stent was also initially placed to avoid the collapse of the cavity and contact with the internal flange of the LAMS [2].

He was admitted again 1 month later with melena, anemia, and a drop in hemoglobin levels from 13.6 to $7.2 \mathrm{~g} / \mathrm{dl}$. Esophagogastroduodenoscopy (EGD) showed migration of the double pigtail stent. Fluoroscopy showed a collection size reduction of 2 to $3 \mathrm{~cm}$. During the EGD, arterial bleeding started from the wall below the internal flange of the LAMS, probably coming from the splenic artery

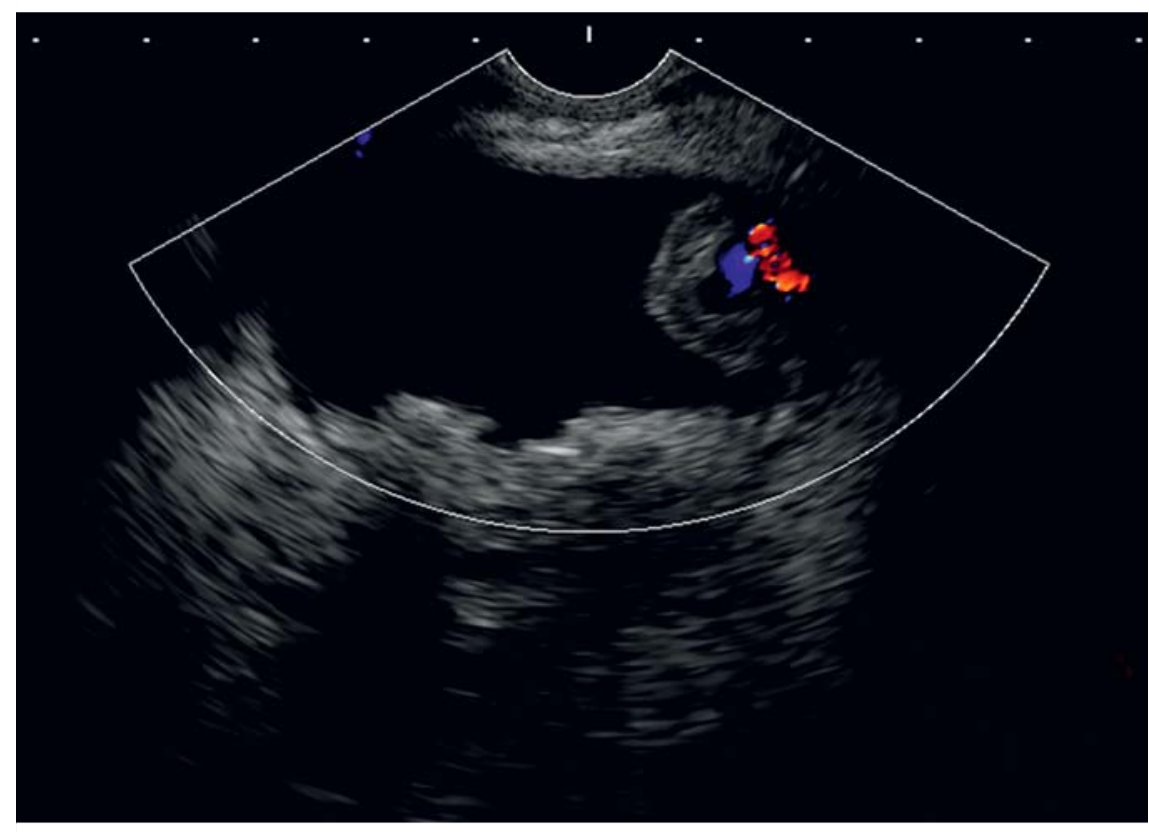

Fig. 2 Endoscopic ultrasound showed the collection was in close contact with the splenic artery.
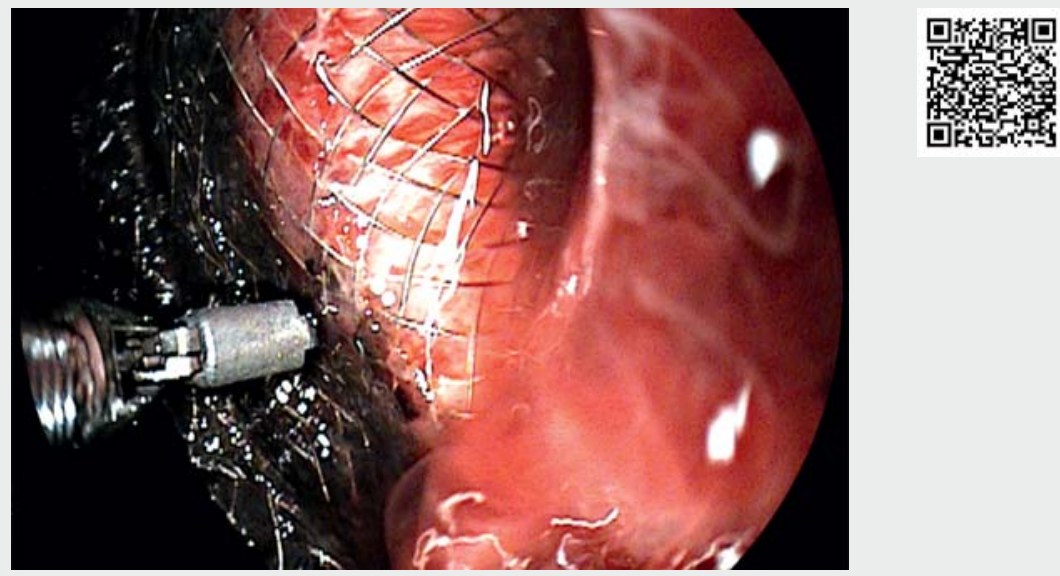

Video 1 Bleeding from a splenic artery pseudoaneurysm was stopped by removing the lumen-apposing metal stent.

( $\triangleright$ Video 1 ). We therefore decided to remove the LAMS.

Computed tomography angiography was then performed, showing irregularities along the profile of the splenic artery, as from small pseudoaneurysm and without spills as in active bleeding ( $\mathbf{F i g . 3 a}$ ). The subsequent selective arteriography

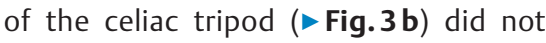
confirm these irregularities. Hence, it 

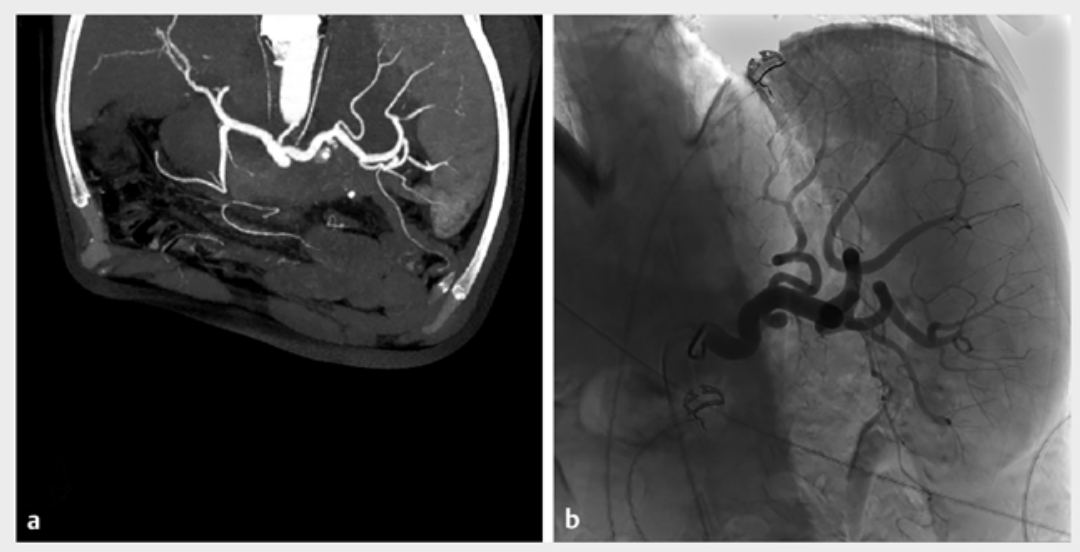

- Fig. 3 a Computed tomography angiography revealed a small pseudoaneurysm of the splenic artery, without spills as in active bleeding. $\mathbf{b}$ Selective arteriography of the celiac tripod did not confirm the pseudoaneurysm.

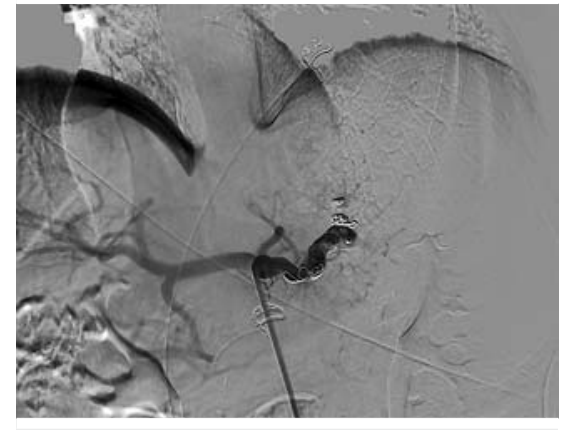

Fig. 4 The main splenic artery is embolized with a 14-mm Vascular Plug II and a Gianturco spiral with good results. Collaterally, a small branch adjacent to the pseudoaneurysm is also embolized at the origin. was collectively decided to perform only the diagnostic study and to pursue close clinical and laboratory follow-up. No further signs of gastrointestinal bleeding were observed, and hemoglobin levels were stable.

A new CT angiography 2 weeks later confirmed the presence of the known pseudoaneurysm of the splenic artery in the mid-distal area. The splenic artery embolization was therefore carried out (॰ Fig.4).

Endoscopy_UCTN_Code_CPL_1AL_2AD

\section{Competing interests}

The authors declare that they have no conflict of interest.
The authors

\section{Fabio De Vincentis, Mario Brancaccio}

Azienda Unità Sanitaria Locale della Romagna, Gastroenterology Unit, Santa Maria delle Croci Hospital, Ravenna, Italy

\section{Corresponding author}

\section{Fabio De Vincentis, MD}

Gastroenterology Unit, Santa Maria delle Croci Hospital, Viale Vincenzo Randi, 5, 48121 Ravenna, Italy

Fax: +39-0544-285325

fabiodevincentis@gmail.com

\section{References}

[1] Walter D, Will U, Sanchez-Yague A et al. A novel lumen-apposing metal stent for endoscopic ultrasound-guided drainage of pancreatic fluid collections: a prospective cohort study. Endoscopy 2015; 47: 63-67

[2] Bang JY, Hasan M, Navaneethan U et al. Lumen-apposing metal stents (LAMS) for pancreatic fluid collection (PFC) drainage: may not be business as usual. Gut 2017; 66: 2054-2056
Bibliography

Endoscopy 2021; 53: E305-E306

DOI $10.1055 / \mathrm{a}-1270-6736$

ISSN 0013-726X

published online 8.10 .2020

(c) 2020. Thieme. All rights reserved.

Georg Thieme Verlag KG, Rüdigerstraße 14, 70469 Stuttgart, Germany

\section{ENDOSCOPY E-VIDEOS}

https://eref.thieme.de/e-videos

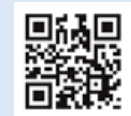

Endoscopy E-Videos is a free access online section, reporting on interesting cases and new techniques in gastroenterological endoscopy. All papers include a high quality video and all contributions are freely accessible online.

This section has its own submission website at

https://mc.manuscriptcentral.com/e-videos 